\title{
O POTENCIAL PARA A DEMOCRACIA PARTICIPATIVA DOS CONSELHOS MUNICIPAIS DE OSASCO E A LIMITADA PARTICIPAÇÃO CIDADÃ
}

\author{
THE POTENTIAL FOR PARTICIPATORY DEMOCRACY OF OSASCO CITY COUNCILS \\ AND LIMITED CITIZEN PARTICIPATION
}

Ivan Alves dos Reis

Companhia de Entrepostos e Armazéns Gerais de São Paulo, SP, Brasil E-mail: ivan.reis@ceagesp.gov.br

Ricardo Lobato Torres

Universidade Tecnológica Federal do Paraná, PR, Brasil E-mail: rltorres@utfpr.edu.br

Recebido em: 29.05.2020 - Aceito em: 01.07.2020

DOI: http://dx.doi.org/10.5902/2526629245269

RESUMO: Este artigo faz uma avaliação das contribuições potenciais à participação cidadã após a institucionalização dos conselhos municipais em Osasco/SP. Como método de investigação, realizou-se uma pesquisa documental da legislação de criação e dos atos dos conselhos no Diário Oficial do Município. Foram analisadas a representação, a composição e as competências dos conseIhos. No mapeamento, constatou-se a existência de 28 conselhos, sendo a maior parte de criação recente, após 2004. A maioria apresenta composição múltipla de conselheiros, demonstrando ampliação do espaço para participação cidadã. Constatou-se uma tendência de atribuição de multicompetências aos conselhos, indicando potencial empoderamento da sociedade civil na formulação de políticas públicas da cidade. No entanto, prevalece a representação vinculada, o que limita a possibilidade de participação dos cidadãos nos conselhos.

Palavras-chave: Conselhos municipais; Participação cidadã; Democracia participativa; Controle social; Políticas públicas.

ABSTRACT: This paper makes an evaluation of the potential contributions to citizen participation after the institutionalization of the municipal councils in Osasco/SP. As a research method, a documentary research was carried out on the breeding legislation and the acts of the councils in the Official Gazette of the Municipality. The representation, composition and competences of the councils were analyzed. In the mapping, it was verified the existence of 28 councils, being 
the most created after 2004. Most of them have multiple composition of councilors, demonstrating the expansion of space for citizen participation. There was a trend towards the attribution of multicompetences to the councils, indicating the potential empowerment of civil society in the formulation of public policies. However, the implied representation prevails, which limits the possibility of citizens' participation in the councils.

Keywords: Municipal councils; Citizen participation; Participatory democracy; Social control; Public policies.

\section{INTRODUÇÃO}

O contexto da redemocratização no Brasil, ocorrido nos anos de 1980, construiu novas dimensões de controle social e redefiniu a participação popular através de novos arranjos políticos, que culminaram na institucionalização dos conselhos municipais (Gohn, 2011; Paludo, 2019). Neste enfoque, as relações entre o Estado e a sociedade sofreram alterações importantes após a promulgação da Constituição da República Federativa do Brasil em 1988, principalmente no que se refere à consolidação da autonomia dos municípios e à descentralização dos recursos públicos com a criação de mecanismos de participação social (Oliveira, Pereira, \& Oliveira, 2007; Paludo, 2019).

O Estado democrático de direito preconizado pela nova constituição promoveu a participação popular através dos conselhos gestores de políticas públicas, juntamente com outras inovações promotoras da democracia, como as conferências, audiências, consultas públicas e ouvidorias (Alencar, Cruxên, Fonseca, Pires, \& Ribeiro, 2013; Alencar \& Reyes Junior, 2018; Jesus Júnior \& Consenza, 2015). A título de ilustração, em um levantamento realizado por Rojas-Buvinich (2014), foram identificados mais de 40 mil conselhos municipais, sendo que a abrangência média dos principais conselhos previstos constitucionalmente nas cidades brasileiras era superior a 90\%. No caso específico do município de Osasco, na Região Metropolitana de São Paulo, até 2004 havia apenas 6 conselhos municipais. Atualmente, existem 28 conselhos, conforme o mapeamento realizado neste artigo.

Esta nova realidade acalorou-se na discussão do modo inovador acerca da participação cidadã por meio dos conselhos. Neste novo paradigma, debateu-se a questão do caráter que deveriam ter, se consultivos, para auscultar a população, e/ou se normativos/representativos, com poder de decisão (Alencar \& Uriella, 2014; Gohn, 2011). A institucionalização dos conselhos gestores de políticas pú- 
blicas acarretou a aproximação entre Estado e sociedade e ampliou o processo de democratização em nível local. A participação política começou a realizar-se não mais apenas pelo voto, mas por outras formas de atuação, tornando-se importante (e muitas vezes obrigatória) a participação popular nas decisões, cujos efeitos seriam sentidos pelas próprias comunidades afetadas (Santos, 2002).

Assim, a institucionalização dos conselhos municipais ganhou relevância como instrumento de promoção da participação cidadã. A mera previsão constitucional, no entanto, não garante a efetiva participação dos cidadãos na tomada de decisão nos assuntos de interesse público. Estudos anteriores têm mostrado que os conselhos municipais têm se constituído de maneira paritária, com a possibilidade de efetiva participação dos cidadãos, mas que a prática dos atos de consulta, deliberação, fiscalização e proposição de políticas nestes espaços públicos tem sido bastante limitada (Alencar et al., 2013; Barddal \& Torres, 2020; Barddal, Torres, \& Polli, 2019; Ribas \& Meza, 2018).

Portanto, visando contribuir com este amplo debate na literatura, o presente artigo buscou avaliar os conselhos municipais, a partir do estudo do caso da cidade de Osasco/SP, considerando o seguinte problema de pesquisa: com a institucionalização e o crescimento no número de conselhos municipais, quais as suas contribuições para a efetiva participação cidadã?

O objetivo geral desta pesquisa foi o de avaliar a promoção da participação cidadã nos conselhos municipais existentes na cidade de Osasco/SP. Além disso, propuseram-se os seguintes objetivos específicos:

a. Mapear os conselhos municipais existentes na cidade de Osasco/SP até 2018;

b. Analisar a legislação e os regimentos existentes para identificar a estrutura de composição e de participação social nos conselhos;

c. Verificar os dispositivos institucionais de previsão e de garantia do direito de representatividade cidadã nos conselhos.

O artigo está organizado em cinco seções, incluindo esta introdução. A segunda seção faz uma revisão de literatura sobre o surgimento dos conselhos gestores de políticas públicas no Brasil, abrangendo os potenciais, os desafios e as limitações encontrados em estudos anteriores para a efetiva participação cidadã. A terceira seção descreve a metodologia da pesquisa realizada para o município de Osasco/SP. A quarta seção apresenta e discute os resultados da pesquisa. Por fim, a quinta seção traz as considerações finais do trabalho. 


\section{REFERENCIAL TEÓRICO}

São diversos os entendimentos acerca da participação cidadã no contexto social. Salles (2014) argumenta que a participação cidadã é um processo ainda em construção e que não se concretiza nos gabinetes do poder, mas através das reivindicações coletivas e gerais, debatidas em espaços públicos e que combinam mecanismos institucionais e sociais, num contexto de luta e dicotomia entre representação e participação.

Para Grau (1998), a noção de participação cidadã é específica, no sentido de se afastar da noção de participação comunitária e da participação mediada por partidos políticos, quando se elege autoridades políticas, pois se manifesta pela intervenção direta dos agentes sociais nas atividades públicas. Outros autores entendem a participação popular como uma condição necessária ao efetivo controle social da gestão pública, a fim de se promover a redução das desigualdades existentes na distribuição dos investimentos nas áreas de políticas públicas, e assim propiciar uma vida mais digna à população marginalizada da sociedade (Barbosa \& Cunha, 2014; Diegues, 2013).

Apesar de um ideal das democracias contemporâneas, estudiosos do tema reconhecem que a participação cidadã ainda enfrenta limites na sociedade brasileira. Dentre eles, destacam-se os de caráter prospectivo, isto é, a capacidade dos espaços de participação direta de promover mudanças estruturais e culturais no engajamento da sociedade com os temas da política. Outros limites estão relacionados ao contexto normativo em que está inserida a participação popular, pois se exige transpor a herança da gestão pública tradicional, que é personalista, patrimonialista e burocrática (Barddal \& Torres, 2020; Grau, 1998; Oliveira et al., 2007; Paludo, 2019; Ribas \& Meza, 2018).

Segundo Gohn (2011), no Brasil foram criados, historicamente, três tipos de conselhos representativos: (1) os conselhos instituídos pelo poder público executivo, cuja atribuição consistia em mediar relações com os movimentos e organizações populares; (2) os conselhos populares, originados dos movimentos sociais ou setores organizados, cuja função era mediar as negociações com o poder público; e (3) os conselhos institucionalizados, criados a partir de leis do poder legislativo, que surgiram a partir de pressões e demandas da população. Para Santos (2002), há três características principais acerca dos conselhos institucionalizados: (i) a participação ocorre por temáticas e não por movimentos sociais, através de áreas que integram o conjunto de representações sociais; (ii) o caráter permanente e abrangente dos conselhos, o que significa acompanhamento amplo no planejamento e na implementação das políticas públicas; e (iii) a autonomia de funcionamento em relação ao governo e seu caráter colegiado entre Estado e sociedade. 
Carneiro (2006) definiu os conselhos gestores de políticas públicas como canais de participação política, de controle público sobre a ação governamental, deliberativos e legalmente institucionalizados de composição paritária (membros governamentais e não-governamentais) de publicização das ações do governo. Gohn (2011) explica que os conselhos gestores constituem inovações institucionais na gestão das políticas públicas no Brasil, determinados por processos políticos que podem atender a diferentes objetivos, como o de contribuir para as mudanças sociais significativas ou para a consolidação de estruturas sociais em transição. Neste aspecto, os conselhos podem atuar como agentes de ampliação do espaço público, atuando como mediadores de conflitos, o que vai de encontro às políticas neoliberais que tentam suprimir estes espaços de participação popular.

Barddal \& Torres (2020) entendem que os conselhos são canais de participação direta, nos quais é possível os cidadãos e os grupos sociais organizados abordarem problemas e demandarem novos direitos ao poder público. Jesus Júnior \& Consenza (2015) explicam que se tratam de espaços públicos de composição plural e paritária entre Estado e sociedade civil, de natureza deliberativa, cuja função é formular e controlar a execução das políticas setoriais. Já para Ribas \& Meza (2018), os conselhos representam um novo modelo de gestão pública, denominado de administração pública societal, no qual o cidadão pode influenciar diretamente nas decisões de interesse público, embora esse ideal ainda não tenha sido atingido no país.

Em estudos anteriores, os autores explicitam o valor potencial dos conselhos municipais como instrumentos de participação democrática, contudo, Wendhausen, Barbosa, \& Borba (2006) apontam para práticas que vão à contramão deste objetivo. Como exemplo, destacam práticas filantrópicas e clientelistas, pois observaram condutas impróprias, como a de manipulação com troca de favores, ações inviabilizadoras da efetivação da democracia almejada pela nova constituição brasileira.

A institucionalização dos conselhos municipais decorreu da previsão constitucional de que a sociedade deveria participar da formulação de políticas públicas locais, num processo de descentralização que supostamente implicaria em fortalecimento dos próprios municípios, com maior atribuição de competências e responsabilidades para os governos locais. Arretche (1996) argumenta que a expectativa da descentralização, enquanto condição para a democratização do processo decisório, deve estar embasada em princípios e valores que partem de instituições concretas, pois autoritarismo e clientelismo podem ser explicados pelo exame da forma pelo qual se associaram historicamente na formação dos distintos estados nacionais, estruturas administrativas do governo central e elites locais e regionais. 
Para Dombrowski (2007), o processo de institucionalização pressupõe dimensões que ocorrem de maneira interdependente: (a) estabilidade, (b) enraizamento, (c) legitimidade e (d) independência. Segundo o autor, estabilidade e institucionalização se correlacionam indissociavelmente de modo que não há como se pensar um sem o outro, do mesmo modo que não há como dizer que algo está institucionalizado se não se encontra enraizado e, por conseguinte, legitimado e reconhecido pela sociedade. No que se refere à independência, explica que as instituições não devem estar subordinadas a interesses personalistas ou particulares, fato que tornaria o nível de institucionalização baixo nesta dimensão.

Para Santos (2002), a institucionalização dos conselhos deve-se aos fatores regulamentares advindos das leis federais que vincularam as transferências de receitas para os municípios por meio do funcionamento destes conselhos como, por exemplo, nas áreas de educação e saúde. Para o autor, muitos destes conselhos foram criados sem uma discussão prévia com as entidades organizadas da comunidade, mas, por outro lado, a partir da criação dos conselhos desenrolou-se um novo padrão de institucionalização da participação, diferentemente das experiências anteriores, quando os conselhos foram criados de forma autônoma pelo Estado, sem articulação com as esferas do poder e sem contemplar a diversidade dos atores sociais.

$\mathrm{Na}$ consolidação do processo de institucionalização dos conselhos de políticas públicas, ressalta-se a promulgação do Decreto Presidencial $n^{\circ} 8.243 / 2014$, cuja finalidade era a de instituir o Sistema Nacional de Participação Social (SNPS), com papel de fortalecer os espaços de diálogo entre Estado e Sociedade, como os conselhos de políticas públicas, comissões, conferências, ouvidorias, mesas de diálogo, fóruns interconselhos, audiências públicas, consultas públicas e ambientes virtuais de participação. Segundo Alencar \& Uriella (2014), o decreto em questão tornou-se polêmico após a sua assinatura, pois alguns defendiam inteiramente o teor do decreto. Segundo os seus defensores, institucionalizar a participação fortalece a democracia, uma vez que aproxima a sociedade do Estado. Isso influiria positivamente na gestão governamental, permitindo aos tomadores de decisão conhecer o impacto das políticas públicas por meio do diálogo com os cidadãos e reforçaria a capacidade de atuar sem interferir no poder legislativo. No mesmo ensejo, os favoráveis ao decreto consideravam competência privativa do Presidente da República expedir atos de organização e funcionamento da administração direta, pois entendem que o decreto apenas organiza os espaços de participação já institucionalizados na prática administrativa do país.

Já os opositores do decreto, segundo Alencar \& Uriella (2014), desacreditavam que a participação social poderia ser útil para consolidar a democracia. Compreen- 
diam que o decreto possuía caráter autoritário, ao criar um sistema de participação que ameaçaria o sistema representativo do poder legislativo brasileiro. As críticas atacaram os conselhos, no sentido de que acarretariam inovações institucionais negativas ao alterar sobremaneira a forma da gestão das políticas públicas no país.

O fato é que, independentemente da criação do SNPS, os conselhos municipais disseminaram-se em todo território nacional em diversos setores da administração pública. Dombrowski (2007) salienta que a simples disseminação, no entanto, não implica necessariamente institucionalização, mas que a base legal confere a eles estabilidade e, nesse aspecto, contribui para o enraizamento destes espaços.

\section{MÉTODO DE PESQUISA}

A pesquisa, de natureza aplicada e com objetivo descritivo, adotou abordagem de análise qualitativa. Foi elaborado, quando possível, a quantificação de atos dos conselhos municipais de Osasco, embora esta abordagem tenha sido secundária nesta pesquisa. Quanto aos procedimentos de investigação, a pesquisa foi dividida em duas etapas: a primeira consistiu em um levantamento bibliográfico não-sistemático sobre o tema de conselhos municipais em trabalhos científicos, tais como artigos, monografias, teses, dissertações, publicações oficiais e livros, pesquisados no Portal Periódicos e no Catálogo de Teses e Dissertações da CAPES. Utilizou-se como palavras-chave os termos: conselhos municipais, participação cidadã, representatividade e institucionalização. Os resultados desse levantamento subsidiaram a discussão da revisão de literatura apresentada na seção anterior.

A segunda fase da pesquisa consistiu em uma pesquisa documental, realizada nos sites oficiais do governo municipal, estadual e federal, imprensa oficial do município, na qual se consultou a legislação e as publicações de atos dos conselhos, ou atos sobre eles, assim como dos referentes aos dispositivos legais que abordassem a questão da participação cidadã. A coleta de dados ocorreu através da investigação das normas, decretos, portarias e publicações oficiais dos respectivos conselhos instituídos na cidade de Osasco, considerando as contribuições para a participação cidadã. Depois, foram mapeados os conselhos municipais existentes na cidade de Osasco em 2018, e então foi proposta uma catalogação e identificação do caráter institucional, com as respectivas leis de institucionalização e as características do modelo de escolha dos representantes, bem como o levantamento das publicações oficiais dos atos ocorridas de janeiro a maio de 2018 no diário oficial do município. Por último, foi efetuada a tabulação dos dados coletados, anotados e inseridos em planilhas formatadas para a análise por meio 
de abordagens quantitativas, em que se utilizou quadros e gráficos ilustrativos.

Para os dados coletados que foram abordados de maneira qualitativa ou quantitativa, utilizaram-se os seguintes parâmetros para tabular e elaborar os gráficos, os quadros e as tabelas, que conformaram evidências que permitiram propor inferências sobre a participação cidadã nos conselhos municipais estudados:

Transparência: Este parâmetro refere-se ao processo de divulgação e de publicidade dos atos dos conselhos. O modo da disposição para acesso das informações que tratem da estrutura organizacional, das normas e das atas internas, da composição dos representantes e dos canais de acesso à comunidade (Pintaudi, 2004).

Modelo de Escolha dos Representantes: Parâmetro que permitiu aferir a forma pela qual se escolhe os representantes no município, indicação monocrática ou democrática por eleições diretas (Draibe, 1998).

Representatividade Social: A representatividade social possibilitou avaliar os canais institucionais inseridos em normas e regulamentos dos conselhos, pelos quais pudessem contribuir e ampliar à participação social, seja por reuniões abertas, fóruns, conferências ou encontros municipais (Draibe, 1998). O procedimento de mapeamento dos conselhos municipais consistiu na catalogação dos conseIhos existentes e de suas respectivas leis de criação. Utilizou-se a consulta nos sites oficiais do município considerando as seguintes características: nome do conselho, ano de criação, legislação de instituição, composição, representação e competência decisória. As informações foram analisadas a partir do modelo de classificação proposto por Draibe (1998).

A Tabela 1 descreve a classificação considerando a representatividade quanto à natureza de composição dos conselhos, podendo ser classificados em bipartites e paritários, bipartites e não paritários, tripartites e paritários, e múltiplos e não paritários, conforme a descrição da Tabela 2.

Tabela 1 - Classificação e características das formas de representação nos conselhos municipais

\begin{tabular}{cl}
\hline Classificação & \multicolumn{1}{c}{ Características } \\
\hline $\begin{array}{c}\text { Representação } \\
\text { vinculadá }\end{array}$ & $\begin{array}{l}\text { A representação das categorias sociais ou profissionais se faz através } \\
\text { de organizações da sociedade civil, que indicam seus representantes; }\end{array}$ \\
$\begin{array}{c}\text { Representação } \\
\text { vinculada funcional }\end{array}$ & $\begin{array}{l}\text { Os membros são indicados por ocuparem um determinado cargo. } \\
\text { Assim, a indicação se faz em razão do cargo e não da pessoa; }\end{array}$ \\
$\begin{array}{c}\text { Representação } \\
\text { não vinculada }\end{array}$ & $\begin{array}{l}\text { Os membros são indicados em razão da expressão de seu trabalho } \\
\text { na sociedade (seja no meio acadêmico ou empresarial). A indicação } \\
\text { decorre diretamente de convite do governo, ou atraves de proces- } \\
\text { sos não vinculantes, nos quais são ouvidos os pares; }\end{array}$ \\
$\begin{array}{c}\text { Representação } \\
\text { mista }\end{array}$ & Ocorrem, simultaneamente, a representação vinculada e não vinculada. \\
\hline
\end{tabular}

Nota: Fonte: Adaptado de Draibe (1998). 
A pesquisa também abrangeu a investigação das competências dos conseIhos, bem como a disposição destas em lei. Nesse sentido, para melhor análise e descrição em face às várias competências previstas na legislação como: deliberativo, fiscalizador, normativo, consultivo etc.; optou-se por classificar os conselhos pela dimensão da sua capacidade decisória, ou seja, monocompetência e multicompetências, conforme explicita a Tabela 3.

Tabela 2 - Classificação de características da forma de composição dos conselhos municipais

\begin{tabular}{cl}
\hline \multicolumn{1}{c}{ Classificação } & \multicolumn{1}{c}{ Caraterísticas } \\
\hline Bipartites e paritários & $\begin{array}{l}\text { Formados por governo e sociedade civil com o mesmo } \\
\text { número para cada segmento. }\end{array}$ \\
Bipartites e não paritários & $\begin{array}{l}\text { Formados por membros governamentais e da sociedade } \\
\text { civil com o número diferente de membros. }\end{array}$ \\
Tripartites e paritários & $\begin{array}{l}\text { Formado por membros do governo, dos trabalhadores e/ou } \\
\text { usuários com o mesmo número de membros. }\end{array}$ \\
Múltiplos e não paritários & $\begin{array}{l}\text { Governo, trabalhadores ou usuários, empregadores ou } \\
\text { prestadores de serviço e, por vezes, representantes } \\
\text { de determinados segmentos da sociedade civil, como } \\
\text { especialistas, com número diferente de membros. }\end{array}$ \\
\hline
\end{tabular}

Nota: Fonte: Autores.

Tabela 3 - Classificação e características das competências dos conselhos

\begin{tabular}{cc}
\hline Classificação & Características \\
\hline Monocompetência & $\begin{array}{c}\text { Definido pela atribuição de uma competência, ex: deliberativo; } \\
\text { Dulticompetênciasido pela atribuição de duas ou mais competências, ex: } \\
\text { deliberativo, normativo, consultivo. }\end{array}$ \\
\hline
\end{tabular}

Nota: Fonte: Autores.

No que se refere às quatro dimensões da institucionalização (estabilidade, enraizamento, legitimidade e independência), ainda que seja verificável a legitimidade representada pelas normas e leis, as outras dimensões ainda necessitam de maior rigor na sua verificação para que os conselhos cumpram seu papel social. No tocante à composição dos conselhos, foi analisado o acervo das leis ordinárias do município de Osasco-SP, disponíveis no site "Leis Municipais" (Plataforma Leis Municipais, 2020), no que se referia aos conselhos gestores, à distribuição participativa e a como está se manifestava dentro da especificação da norma.

Nesse sentido, o estudo abordou o mapeamento e a avaliação dos conseIhos municipais na cidade de Osasco, compreendendo o dimensionamento e a institucionalização na cidade, pretendendo assim verificar a perspectiva da inserção democrática no ambiente local. Buscou-se entender as nuances desta inserção, 
através de um balanço da legislação, do mapeamento dos conselhos existentes e de seus aspectos políticos de participação cidadã na gestão das políticas sociais.

\section{APRESENTAÇÃO E DISCUSSÃO DOS RESULTADOS}

$\mathrm{Na}$ consulta realizada sobre as legislações de instituição, foram identificados 28 conselhos municipais na cidade de Osasco-SP. Além disso, constatou-se que já existiam conselhos antes da Constituição Federal de 1988, exemplificados pelo Conselho Municipal de Impostos e Taxas, criado em 1962, e pelo Conselho Municipal de Trânsito, instituído em 1967. O mais recente deles é o Conselho Municipal de Políticas Públicas sobre Drogas, instituído em 2018 pela Lei Ordinária $n^{\circ} 4875 / 2018$. A Tabela 4 apresenta a relação dos conselhos de Osasco em ordem cronológica de sua instituição.

Ainda, com base nos dados da Tabela 4, nota-se que no período de 2004 a 2007 foram criados 14 conselhos municipais, demonstrando-se como o período mais frutífero na criação de novos conselhos. Por outro lado, houve períodos em que não se constatou nenhum registro da instituição de conselhos, como verificado nos anos de 2003, 2016 e 2017.

Buscou-se também comparar a quantidade de conselhos com a proporção do número de habitantes em relação a outras cidades do estado de São Paulo, a fim de avaliar se há convergência ou divergência com outras práticas municipais. Para este exercício, foram selecionados os municípios de Campinas, Santo André e Piracicaba, cujos resultados são apresentados na Tabela 5.

$\mathrm{Na}$ comparação entre população e número de conselhos existentes, não foi possível identificar qualquer tipo de relação entre estas variáveis, pois no comparativo entre as cidades, Piracicaba apresentou quase metade da população de Osasco, e ambas possuem a mesma quantidade de conselhos municipais. Neste mesmo enfoque, Santo André possui população superior a Osasco e Piracicaba e, no entanto, existe uma quantidade de conselhos municipais inferior. Portanto, não é possível afirmar que existe um padrão ou um número ideal de conselhos instituídos pelos municípios em razão do seu tamanho populacional. Isto caracteriza, guardadas as devidas limitações dos exemplos supracitados, uma heterogeneidade na quantidade de conselhos que os municípios paulistas decidem instituir, o que impacta também na capacidade do cidadão de participar diretamente das decisões na formulação de políticas públicas no nível local. 
Tabela 4 - Relação dos conselhos municipais de Osasco por ano de instituição

\begin{tabular}{|c|c|c|}
\hline \# & Nome do Conselho & Ano \\
\hline 1 & Conselho Municipal de Impostos e Taxas & 1962 \\
\hline 2 & Conselho Municipal de Trânsito & 1967 \\
\hline 3 & Conselho Municipal de Educação & 1998 \\
\hline 4 & Conselho do Idoso & 1998 \\
\hline 5 & Conselho Municipal da Pessoa Portadora de Deficiência & 1999 \\
\hline 6 & Conselho Municipal de Merenda Escolar & 2001 \\
\hline 7 & Conselho da Comunidade Negra da Casa da Cultura Afro-Brasileira & 2004 \\
\hline 8 & Conselho Municipal de Prevenção aos Acidentes de Trabalho e Doenças Ocupacionais & 2004 \\
\hline 9 & Conselho Municipal de Assistência Social & 2004 \\
\hline 10 & Conselho Municipal de Defesa Civil & 2005 \\
\hline 11 & Conselho Municipal de Saúde & 2005 \\
\hline 12 & Conselho Municipal de Segurança Urbana & 2005 \\
\hline 13 & Conselho Municipal dos Direitos da Mulher & 2005 \\
\hline 14 & Conselho Municipal de Segurança Alimentar e Nutricional & 2006 \\
\hline 15 & Conselho Municipal de Juventude de Osasco-SP & 2006 \\
\hline 16 & Conselho e o Fundo Municipal de Política Urbana e Habitacional & 2006 \\
\hline 17 & Conselho Municipal de Esporte e Lazer & 2006 \\
\hline 18 & Conselho Municipal de Acompanhamento e Controle Social do Fundeb & 2007 \\
\hline 19 & Conselho Municipal de Turismo & 2007 \\
\hline 20 & Conselho Municipal de Gestão Compartilhada Educação & 2007 \\
\hline 21 & Conselho Municipal de Defesa do Meio Ambiente & 2008 \\
\hline 22 & Conselho Municipal de Contribuintes & 2009 \\
\hline 23 & $\begin{array}{c}\text { Conselho Municipal de Defesa e Preservação do Patrimônio Histórico, Artístico e } \\
\text { Cultural }\end{array}$ & 2010 \\
\hline 24 & Conselho Municipal de Política Cultural & 2011 \\
\hline 25 & Conselho Municipal dos Direitos da Criança e do Adolescente & 2013 \\
\hline 26 & Conselho Municipal de Mobilidade Urbana & 2014 \\
\hline 27 & Conselho e o Fundo Municipal de Promoção da Igualdade Racial & 2015 \\
\hline 28 & Conselho Municipal de Políticas Públicas sobre Drogas & 2018 \\
\hline
\end{tabular}

Nota: Fonte: Autores.

Tabela 5 - Número de conselhos por mil habitantes: Campinas, Osasco, Santo André e Piracicaba, 2018

\begin{tabular}{ccccc}
\hline Indicador / Cidades & Campinas & Osasco & Santo André & Piracicaba \\
\hline Conselhos & 42 & 28 & 19 & 28 \\
População & 1.182 .429 & 697.886 & 715.231 & 397.227 \\
Conselhos / mil habitantes & 0,0355 & 0,0401 & 0,0266 & 0,0705
\end{tabular}

Nota: Fonte: Autores com base em: Instituto Brasileiro de Geografia e Estatística (2020), Prefeitura Municipal de Campinas (2020), Prefeitura Municipal de Osasco (2020), Prefeitura Municipal de Piracicaba (2020) e Prefeitura Municipal de Santo André (2020). 
A Figura 1 ilustra a composição dos conselhos mapeados. Esclarece-se, contudo, que não foi considerado no cálculo o Conselho de Impostos e Taxas, uma vez que este se encontra expirado pela legislação do município e, portanto, inativo. Neste contexto, foram considerados os 27 conselhos municipais ativos, tabulados e classificados conforme suas respectivas composições. Nesta classificação, verificou-se a tendência para a composição de conselhos múltiplos e não paritários, no percentual de 44,44\%. O resultado denotou a ampliação dos espaços participativos na esfera pública local, resultando numa multiplicidade aberta aos diversos setores da sociedade, pois a constatação da tendência apontada presume um cenário político aberto ao diálogo entre o governo local e os trabalhadores, os usuários, os empregadores, os prestadores de serviços e os representantes de segmentos da sociedade civil, como os especialistas, ainda que não seja paritário.

Figura 1 - Composição dos Conselhos Municipais de Osasco

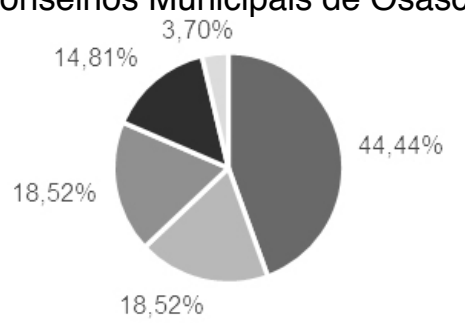

- Múltiplo e não paritário = Tripartite e não paritário - Bipartite e paritário - Bipartite e não paritáro "Tripartite e paritário Fonte: Autores.

Por outro lado, a composição tripartite e paritário representou 3,7\% dos conselhos investigados, fato do qual tripartite e não paritário responde por $18,52 \%$, seguido pela bipartite e paritário. Não se verificou uma explicação razoável a estes casos, contudo, compreende-se que haja a razão de conveniência e necessidade conforme a peculiaridade de instauração de cada conselho.

Haja vista os resultados ora demonstrados, investigou-se dentro do mesmo enfoque da composição o procedimento de escolha da representação contido na legislação criadora dos conselhos. Neste tocante, o procedimento foi o de averiguar como a norma instruía a escolha dos representantes e quais competências estavam atribuídas a estes conselhos. Durante a investigação documental, constatou-se que estas competências e/ou atribuições são variadas.

Diante da variância observada na quantidade de competências em relação à representação, utilizou-se a seguinte classificação como base para a organização dos dados coletados em referência ao binômio representação e competência dos 
conselhos: vinculada e monocompetência; vinculada e multicompetências; mista e monocompetência; e mista e multicompetências. Considerou-se monocompetência o conselho que apresentava em sua lei de criação apenas uma competência, e multicompetências o conselho que apresentava duas ou mais competências explicitadas em sua lei de criação.

A classificação proposta se justificou devido à grande quantidade de informações dispersas, de tal maneira que este critério possibilitou organizar e tabular as informações ordenadamente, para que assim se realizasse uma análise razoável da forma de representação e das competências atribuídas aos conselhos, conforme exposto na Figura 2.

Figura 2 - Representação e Competências dos Conselhos Municipais de Osasco

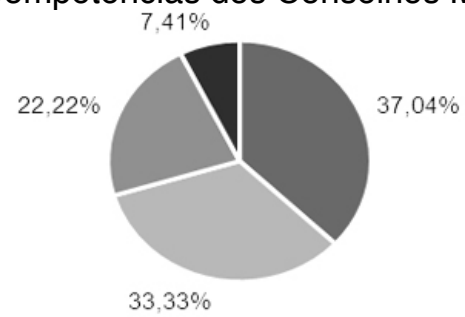

- Vinculada e multicompetências = Vinculada e monocompetência " Mista e multicompetências " Mista e monocompetência Fonte: Autores.

A questão da representação refere-se ao modelo de indicação ou da escolha dos membros dos conselhos, enquanto as competências referem-se ao conjunto de atribuições e responsabilidades estabelecidas em lei. Neste sentido, a pesquisa mostrou que $37,04 \%$ dos conselhos municipais de Osasco possuem representação vinculada e com duas ou mais competências legais, ou seja, a indicação dos membros representantes se faz nas próprias organizações governamentais e não governamentais com cadeira cativa no conselho, independendo da forma de escolha, enquanto as competências se traduzem em quantidade de atribuições. Em segundo lugar, verificam-se conselhos de representação vinculada e de monocompetência, representando $33,33 \%$ do total. Nesse sentido, essas duas categorias representam mais de $70 \%$ dos conselhos municipais de Osasco.

Esses resultados demonstraram que há uma tendência para a criação de conselhos com vagas representativas vinculadas a órgãos governamentais e não governamentais. Se analisado apenas da perspectiva de competências atribuídas em lei, quase $60 \%$ é caracterizado como de multicompetências. Assim, a menor parte tem apenas o caráter consultivo ou deliberativo. Dessa forma, a maior parte 
dos conselhos do município possui de duas a até quatro competências previstas em lei, o que, do ponto de vista formal, representa um potencial de participação direta na gestão das políticas públicas locais.

A Figura 2 demonstra que a soma dos índices destes que possuem duas ou mais competências, desconsiderando o caráter representatividade, simbolizou $59,26 \%$. O caráter diversificado das competências segue além do deliberar e do consultar, ganhando novos perfis nas linhas políticas de exercício funcional, como, por exemplo: fiscalizar, avaliar, controlar, coordenar, judiciar e normatizar. Constata-se isto por mais que esta pesquisa não tenha analisado a quantidade de atribuições em comparação com o ano de instauração dos conselhos, tema que poderá ser explorado em pesquisa futura.

A título de exemplo desta tendência de multicompetências entre os conseIhos municipais, cita-se o caso do Conselho Municipal de Políticas Públicas sobre Drogas, instituído pela Lei Municipal n. ${ }^{\circ}$ 4.875/2018. No artigo segundo desta lei, estabeleceu-se que o conselho tem por finalidade desempenhar o papel: consultivo, deliberativo, normativo e fiscalizador. Esta atribuição ocorre em outros conselhos, como o Conselho Municipal de Política Pública e Habitacional, Conselho Municipal de Turismo, entre outros.

As conquistas institucionais proporcionadas aos conselhos municipais, através da legislação, em sua natureza de composição, representação e capacidade decisória, permitiram que se verificasse, nesta pesquisa, que a maioria dos conseIhos possuem composição múltipla no que se refere aos segmentos representativos da sociedade participante e são imbuídos de duas ou mais competências. No entanto, ainda que as informações coletadas possam ser aparentemente positivas, no sentido de que os conselhos municipais possuem valor potencial de participação democrática e de inovações institucionais, cuja função é mediar as negociações com o poder público, esses podem ser orientados por práticas que vão de encontro com seu objetivo institucional. Wendhausen et al. (2006) explicam que muitos conselhos são utilizados de modo manipulativo, sendo apenas objetos formais e protocolares, que existem para o recebimento de verbas públicas. Além disso, há desigualdade entre os representantes quanto à capacidade de influência política, e isso se reflete na ausência de mecanismos de controle sobre a representatividade. É preciso reconhecer os limites da participação cidadã nos conselhos, no sentido de que há ainda desafios de mudanças estruturais e culturais.

Não obstante, realizou-se também a pesquisa para averiguar o parâmetro da transparência nos conselhos. Para isso, foram investigadas as publicações ocorridas na Imprensa Oficial do Município de Osasco (IOMO), numa abordagem 
quantitativa dos atos. Neste aspecto, a contagem estabelecida foi definida em uma unidade por edição publicada. Desconsiderou-se a quantidade de atos numa mesma publicação, mas fixou atos por publicação. Assim, pesquisou-se as edições de número 1432 a 1499 da IOMO, referentes ao período de janeiro a maio de 2018. Foram investigadas dentre as 67 (sessenta e sete) edições do Diário Oficial do Município assuntos pertinentes aos conselhos municipais da cidade de Osasco-SP e seus atos para averiguar o quesito transparência no que se referia à periodicidade da publicização dos atos. Dentre as informações investigadas, o que se constatou em sua maioria referia-se a editais, normas de eleição, nomeações, atas de reunião, editais de convocação, reuniões ordinárias, decisões, despachos diversos e etc.

Os dados coletados foram tabulados e classificados ordenadamente, de forma que se obteve a Tabela 6, que apresentou a quantificação das publicações, o nome dos conselhos e a periodicidade das edições da imprensa oficial municipal abrangidas na pesquisa.

A Tabela 6 foi ordenada pela quantidade de publicações em ordem decrescente, na qual observou-se que o Conselho Municipal de Direitos da Criança e do Adolescente apresentou considerável quantidade de publicações se comparado aos demais conselhos. O total deste conselho representou $28,78 \%$ do total de publicações, seguido do Conselho Municipal de Assistência Social 16,67\% e o Conselho Municipal de Saúde $15,15 \%$. Os demais apresentaram reduzida manifestação dos seus atos, resumindo-se à quantidade de 1 a 4 publicações, que representaram o percentual de $1,51 \%$ a $6,06 \%$ do total ocorrido no período pesquisado.

Tabela 6 - Publicações de atos dos conselhos municipais de Osasco, janeiro a maio de 2018

\begin{tabular}{clc}
\hline$\#$ & \multicolumn{1}{c}{ Nome do Conselho } & Qtd. \\
\hline 1 & Conselho Municipal dos Direitos da Criança e do Adolescente & 19 \\
2 & Conselho Municipal de Assistência Social & 11 \\
3 & Conselho Municipal de Saúde & 10 \\
4 & Conselho Municipal do Idoso & 4 \\
5 & Conselho e o Fundo Municipal de Política Urbana e Habitacional & 4 \\
6 & Conselho Municipal de Política Cultural - COMCULTURA & 4 \\
7 & Conselho Municipal de Acompanhamento e Controle Social do Fundeb & 3 \\
8 & Conselho Municipal de Contribuintes & 2 \\
9 & Conselho Municipal de Defesa do Meio Ambiente - CONDEMA & 2 \\
10 & Conselho e o Fundo Municipal de Promoção da Igualdade Racial (COMPIR) & 1 \\
11 & Conselho Municipal de Educação & 1 \\
12 & Conselho Municipal de Esporte e Lazer & 1
\end{tabular}


13 Conselho Municipal de Merenda Escolar 1

14 Conselho Municipal de Mobilidade Urbana 1

15 Conselho Municipal de Políticas Públicas sobre Drogas 1

16 Conselho Municipal para Assuntos da Pessoa Portadora de Deficiência 1

17 Conselho da Comunidade Negra da Casa da Cultura Afro-Brasileira 0

18 Conselho Municipal de Defesa Civil - Comundec 0

19 Conselho Municipal de Defesa e Preservação do Patrimônio Histórico, 0 Artístico e Cultural - CODEPA

20 Conselho Municipal de Gestão Compartilhada Educação 0

21 Conselho Municipal de Impostos e Taxas (norma vigência esgotada) 0

22 Conselho municipal de Juventude de Osasco-SP 0

23 Conselho Municipal de Prevenção aos Acidentes de Trabalho e Doenças 0 Ocupacionais

24 Conselho Municipal de Segurança Alimentar e Nutricional 0

25 Conselho Municipal de Segurança Urbana 0

26 Conselho Municipal de Trânsito 0

27 Conselho Municipal de Turismo 0

28 Conselho Municipal dos Direitos da Mulher 0

Nota: Fonte: Autores com base em Prefeitura Municipal de Osasco. (2020).

A média de atos dos conselhos por publicação oficial no período foi de 2,36 no período, sendo a média de publicações mensais de 13,2. Revela-se, neste contexto, um baixo índice de atos publicados, considerando o universo total de 28 (vinte e oito) conselhos existentes na cidade de Osasco-SP. O percentual total de conselhos que efetuaram publicações representou $57,14 \%$, enquanto o total que não efetuou nenhuma publicação representou $42,86 \%$. É importante salientar que os conselhos em que se verificaram maior quantidade de publicações, os três primeiros, possuem bases normativas disciplinadas em lei federal, porquanto a instituição destes conselhos atende a requisitos necessários para receber e movimentar recursos federais, bem como atender aos preceitos da Constituição Federal em prol do desenvolvimento de políticas públicas em nível estadual e municipal.

\section{CONSIDERAÇÕES FINAIS}

Este artigo investigou as contribuições à participação cidadã dos conselhos municipais instituídos ao longo das últimas décadas na cidade de Osasco-SP. Foi constatado que a cidade possui 28 conselhos de políticas públicas institucionalizados por lei municipal. Contudo, o levantamento histórico mostrou que em 2004 havia apenas 6 conselhos, e em meados de 2007 já existiam 20 institucionaliza- 
dos, o que revela o seu rápido crescimento nos últimos anos.

Quanto à composição, os resultados da pesquisa revelaram que, em sua maioria, a composição de conselheiros é múltipla, demonstrando ampliação do espaço para participação cidadã. Esse fato denota a preocupação do poder público em promover o acesso aos diversos segmentos da sociedade civil nos debates de interesse público municipal.

Em relação às atribuições dos conselhos, constatou-se uma tendência de atribuição de duas ou mais competências, o que significa dizer que houve intenção de ampliação e empoderamento da sociedade civil nas decisões e controle das políticas públicas do município, pelo menos do ponto de vista legal e formal. Contudo, requer-se uma análise qualitativa mais aprofundada do exercício efetivo dessas atribuições pelos membros não governamentais em tais conselhos, como a já elaborada em outros estudos (Barddal \& Torres, 2020; Barddal et al., 2019).

No que diz respeito à representatividade nos conselhos, verificou-se uma tendência de instituição de conselhos com representação vinculada, isto é, aquela que se caracteriza pela escolha de membros internos a instituições ou organizações pré-determinadas, o que pode representar uma barreira de acesso à população em geral. A indicação dos conselheiros dentro também é variada, podendo ser por eleição interna ou designação. Novamente, a contribuição à efetiva participação cidadã mostra-se limitada quando as vagas nos conselhos são previamente vinculadas, havendo o risco de cooptação e concentração de interesses em grupos restritos da sociedade civil. Essa evidência reforça o distanciamento de um ideal de administração pública societal, como já apontados em pesquisas anteriores (Ribas \& Meza, 2018; Wendhausen et al., 2006).

Embora não tenha sido o foco central do trabalho, constatou-se ainda, no tocante à transparência dos atos dos conselhos, um percentual elevado de conseIhos municipais que não apresentou informações e/ou publicações, conforme preconizado pela lei. Neste sentido, a ausência da transparência conforma-se como outro limitante à participação cidadã no controle social, principalmente quando consideradas competências consultiva e de fiscalização da política pública, as quais foram atribuídas à maioria dos conselhos. Essa dificuldade operacional de consulta e o problema da transparência foram apontados em outros estudos de caso, denotando a possibilidade de ser um problema mais geral do que apenas o caso estudado nesta pesquisa (Barddal \& Torres, 2020; Barddal et al., 2019).

A questão da participação cidadã como processo de construção de políticas públicas, como explica Salles (2014), passou a se concretizar em espaços 
públicos e, apesar de combinar mecanismos institucionais e sociais, a dicotomia representação e participação ainda se faz presente. Por outro lado, a institucionalização dos conselhos de certa maneira permitiu à sociedade algum controle sobre as ações do governo, embora, conforme visto em artigos e pesquisas, ainda sejam utilizados por mero capricho legal e por requisito obrigatório para a movimentação de recursos e para o acesso a benfeitorias da União. Cumpre reiterar que a sociedade deve avaliar os impactos dos conselhos, cobrar dos governos mecanismos de controle através de pesquisas e da garantia de voz representativa dentro destes espaços democráticos para galgar poder de decisão popular.

Por fim, considerando que os conselhos municipais são uma realidade contemporânea, estes devem ser permanentemente avaliados em função do potencial inerente à consolidação da democracia participativa. Deve-se ponderar, porém, os desafios desse processo de consolidação, marcado por uma transição cultural e estrutural, no que se refere especificamente ao processo de inserção democrática da população nas decisões políticas, que exige ainda amadurecimento da sociedade enquanto agente fundamental nos conselhos municipais.

\section{REFERÊNCIAS}

Alencar, J. L. O., Cruxên, I., Fonseca, I., Pires, R., \& Ribeiro, U. (2013). Participação social e desigualdades nos conselhos nacionais. Sociologias, 15(32), 112-146. https://doi.org/10.1590/S1517-45222013000100006.

Alencar, J. L. O., \& Reyes Junior, E. (2018). Atuação da sociedade no Conselho Nacional de Turismo: demandas e rede de relacionamentos. Administração Pública e Gestão Social, 10(3), 170-178. Recuperado de https://periodicos. ufv.br/apgs/article/view/5317.

Alencar, J. L. O., \& Uriella, C. R. (2014). O decreto sobre a participação social no governo federal e a bendita polêmica. Boletim de Análise Político-Institucional, (6), 23-28. Recuperado de http://repositorio.ipea.gov.br/handle/11058/5935.

Arretche, M. (1996). Mitos da descentralização: mais democracia e eficiência nas políticas públicas? Revista Brasileira de Ciências Sociais, 11(31), 44-66. Recuperado de http://www.anpocs.com/images/stories/RBCS/rbcs31_03. pdf.

Barbosa, A. Q. dos S., \& Cunha, M. M. V. (2014). A importância dos conselhos de políticas públicas para a efetivação dos direitos fundamentais e consolidação da democracia. In E. D. Machado, J. M. Bertaso, \& L. R. da Cunha (Eds.). Direitos Fundamentais e Democracia III (pp. 273-300). Florianópolis: 
CONPEDI. Recuperado de http://publicadireito.com.br/publicacao/ufsc/livro. php?gt=211.

Barddal, F. M. E., \& Torres, R. L. (2020). Efetividade da participação cidadã nos conselhos municipais de Curitiba. Urbe. Revista Brasileira de Gestão Urbana, 12. https://doi.org/10.1590/2175-3369.012.e20190045.

Barddal, F. M. E., Torres, R. L., \& Polli, S. A. (2019). CONCITIBA: Análise da democracia participativa na gestão 2014-2016. Revista Brasileira de Planejamento e Desenvolvimento, 8(1), 17-37. https://doi.org/10.3895/rbpd.v8n1.7976.

Carneiro, C. B. L. (2006). Conselhos de políticas públicas: desafios para sua institucionalização. In E. Saraiva \& E. Ferrarezi (Eds.). Políticas Públicas (2. ed). Brasília: ENAP, pp. 149-166. Recuperado de https://www.ipea.gov.br/participacao/images/pdfsconselhos/carneiro\%20c\%20b\%20l\%20conselhos\%20 de\%20polticas\%20pblicas\%20desfios\%20para\%20sua\%20institucionalizao.pdf.

Diegues, G. C. (2013). O controle social e participação nas políticas públicas: o caso dos conselhos gestores municipais. Revista Nau Social, 4(6), 8293. Recuperado de https://portalseer.ufba.br/index.php/nausocial/article/ view/31241.

Dombrowski, O. (2007). Os conselhos vistos por fora: um estudo sobre a institucionalização dos conselhos municipais. Tempo Da Ciência, 14(27), 121134. Recuperado de http://e-revista.unioeste.br/index.php/tempodaciencia/ article/view/1568.

Draibe, S. M. (1998). A nova institucionalidade do sistema brasileiro de políticas sociais: os conselhos nacionais de políticas setoriais. Caderno de Pesquisa NEPP, (25), 1-26. Recuperado de https://www.nepp.unicamp.br/biblioteca/ periodicos/issue/view/71/CadPesqNepp35.

Gohn, M. da G. (2011). Conselhos gestores e participação sociopolítica (4. ed.). São Paulo: Editora Cortez.

Grau, N. C. (1998). Repensando o público através da sociedade: novas formas de gestão pública e representação social. Rio de Janeiro: Editora Revan.

Instituto Brasileiro de Geografia e Estatística. (2020). Brasil em síntese: São Paulo, Osasco, Panorama. Recuperado de https://cidades.ibge.gov.br/brasil/sp/ osasco/panorama.

Jesus Júnior, G. de, \& Consenza, L. Z. C. (2015). A importância da participação popular através dos Conselhos Municipais na formulação e aplicação de políticas públicas no âmbito local. Jus Navigandi. Recuperado de https://jus. 
com.br/artigos/44883/a-importancia-da-participacao-popular-atraves-dos-conselhos-municipais-na-formulacao-e-aplicacao-de-politicas-publicas-no-ambito-local.

Oliveira, V. C. da S., Pereira, J. R., \& Oliveira, V. A. R. de. (2007). Paradigmas de administração pública e conselhos gestores municipais: velhas abordagens de gestão e novos arranjos institucionais? In Encontro Nacional da Associação Nacional de Pós-Graduação em Administração (pp. 1-16). Rio de Janeiro: ANPAD. Recuperado de http://www.anpad.org.br/admin/pdf/APS-B1528.pdf.

Paludo, J. R. (2019). Abordagem sobre a participação no Governo Lula. Administração Pública e Gestão Social, 11(3), 1-17. Recuperado de http://www. redalyc.org/articulo.oa?id=351559268004.

Pintaudi, S. M. (2004). Participação cidadã e gestão urbana. Cidades, 1(2), 169180. Recuperado de http://revista.fct.unesp.br/index.php/revistacidades/ article/view/475.

Plataforma Leis Municipais. (2020). Leis de Osasco, SP - digitalização, compilação e consolidação da legislação municipal. Recuperado de https://leismunicipais.com.br/legislacao-municipal/5123/leis-de-osasco.

Prefeitura Municipal de Campinas. (2020). Conselhos Municipais de Campinas. Recuperado de http://www.campinas.sp.gov.br/governo/gestao-e-controle/ conselhos.php.

Prefeitura Municipal de Osasco. (2020). Imprensa Oficial do Município de Osasco. Recuperado de http://www.osasco.sp.gov.br/imprensa-oficial.

Prefeitura Municipal de Piracicaba. (2020). Portal dos Conselhos Municipais de Piracicaba. Recuperado de http://conselhos.piracicaba.sp.gov.br.

Prefeitura Municipal de Santo André. (2020). Conselhos Municipais. Recuperado de https://www2.santoandre.sp.gov.br/index.php/2013-03-20-17-29-08/ conselhos-municipais.

Ribas, J. A. N., \& Meza, M. L. F. G. de. (2018). Os Conselhos Gestores de Políticas Públicas: espaços de consolidação da administração pública societal? Administração Pública e Gestão Social, 10(1), 45-54. Recuperado de https:// periodicos.ufv.br/apgs/article/view/5261.

Rojas-Buvinich, D. P. (2014). O mapeamento da institucionalização dos conselhos gestores de políticas públicas nos municípios brasileiros. $R e$ vista de Administração Pública, 48(1), 55-82. https://doi.org/10.1590/ S0034-76122014000100003. 
Salles, H. da M. (2014). Gestão democrática e participativa (3. ed.). Florianópolis; Brasília: UFSC; UAB, CAPES.

Santos, M. R. M. dos. (2002). Conselhos municipais e a participação cívica na gestão das políticas públicas: o caso da metrópole fluminense. Cadernos Metrópole, (7), 97-112. Recuperado de https://revistas.pucsp.br/metropole/ article/view/9261/6871.

Wendhausen, Á. L. P., Barbosa, T. M., \& Borba, M. C. de. (2006). Empoderamento e recursos para a participação em conselhos gestores. Saúde e Sociedade, 15(3), 131-144. https://doi.org/10.1590/s0104-12902006000300011. 